\title{
Trichomegaly and scalp hair changes following treatment with erlotinib in pulmonary adenocarcinoma patients: A case report and literature review
}

\author{
HUA ZHENG* , HONGMEI ZHANG* , TONGMEI ZHANG* , QUNHUI WANG* , FANBIN HU and BAOLAN LI \\ Department of Oncology, Beijing Chest Hospital, Capital Medical University, Beijing 101149, P.R. China
}

Received February 27, 2015; Accepted April 1, 2016

DOI: $10.3892 /$ etm.2016.3460

\begin{abstract}
Erlotinib is among the oral EGFR-tyrosine kinase inhibitors used to treat non-small cell lung cancer. The common side effects of erlotinib include acne form rash and diarrhea. Eyelash trichomegaly and alterations of scalp hair are rarely observed symptoms. In the present study, we report changes in eyelash trichomegaly and scalp hair in six cases of pulmonary adenocarcinoma patients that had been administered erlotinib. The symptoms of eyelash trichomegaly include curly, irregular, excessively long and brittle eyelashes, and alterations of scalp hair include curly or straight, brittle, fine or rigid, reduced growth rate and volume. Since these side effects does not substantially impact patient quality of life, no treatments were administered. These changes in eyelashes and scalp hair gradually disappeared after withdrawal of erlotinib.
\end{abstract}

\section{Introduction}

Lung cancer is the most common cause of cancer-associated mortality cause in the world (1). In particular non-small cell lung cancer (NSCLC) accounts for $\sim 80 \%$ of all lung cancer cases (1). NSCLC is commonly diagnosed at the advanced stages of the disease, and platinum-based chemotherapy is the standard treatment for advanced NSCLC, with response rates to currently-used regimens of 30-40\% (2). However, patients eventually develop resistance to chemotherapy, resulting in a median survival of only 8-10 months (3).

Targeted therapies are another option in patients who harbor mutations on key genes, such as in the epidermal growth factor receptor (EGFR) and anaplastic lymphoma kinase genes (4-9). EGFR-tyrosine kinase inhibitors (EGFR-TKIs) are used in the treatment of advanced NSCLC, particularly in patients

Correspondence to: Professor Baolan Li, Department of Oncology, Beijing Chest Hospital, Capital Medical University, 97 Machang Road, Tongzhou, Beijing 101149, P.R. China

E-mail: libaolan1109@163.com

${ }^{*}$ Contributed equally

Key words: erlotinib, side effect, trichomegaly, scalp hair with activating mutations in the EGFR gene (4-8). Two types of mutation have been reported to comprise up to $90 \%$ of all activating EGFR mutations, including the deletion in exon 19, clustered around the amino-acid residues 747-750, and a specific point mutation in exon 21 (L858R) (10-12). The progression-free survival (PFS) of the first-line EGFR-TKI drugs ranges between 8.4 and 13.1 months (4-8), and the overall survival reached 34.8 months (13). The common side effects of EGFR-TKIs include rash, diarrhea, fatigue and loss of appetite (14).

Erlotinib is an oral EGFR-TKI used in the treatment of advanced NSCLC, particularly for patients with activating mutations in the EGFR gene. EGFR is expressed in basal and suprabasal layers of the epidermis, in sebaceous glands and in the outer root sheath of the hair follicles (15), which may explain the cutaneous side effects of erlotinib, including acneform rash. Along with the wide use of erlotinib, there is an increasing number of studies reporting uncommon side effects, such as cardiac adverse effects (16), interstitial lung disease (17) and ocular side effects (18). The present study described the cases of 6 pulmonary adenocarcinoma patients receiving erlotinib, who presented rare side effects associated with epidermis, such as trichomegaly and alterations of scalp hair (Table I). In the present study, all patients provided written informed consent.

\section{Case report}

Case 1. A 29-year-old female patient presented with a cough and sputum in March 2013. She underwent chest computed tomography (CT) scan which showed miliary nodules diffused at bilateral lobes of lungs. Bronchoscopic biopsy (Olympus-BF-260; Olympus Corp., Tokyo, Japan). ) was performed and a diagnosis of stage cT4N2M1b lung adenocarcinoma primarily located at right upper lobe of lung, metastasis in both lungs and mediastinal lymph nodes was made following pathological (hematoxylin and eosin staining) and immunohistochemical (thyroid transcription factor-1) examination. First line treatment with $1,250 \mathrm{mg} / \mathrm{m}^{2}$ gemcitabine (days 1 and 8; Lilly France, Neuilly-sur-Seine, France) plus $75 \mathrm{mg} / \mathrm{m}^{2}$ cisplatin (day 1; Qilu Pharmaceutical Co., Ltd., Jinan, China) was administered for two cycles (21 days). Simultaneously, EGFR mutation with a deletion at exon 19 (c.2235_2249del15) was detected in tumor tissue by 
direct Sanger sequencing test. Image examination with CT and magnetic resonance imaging (MRI) was performed after two cycles of chemotherapy. Chest CT showed no significant change in the diffuse miliary nodes. Brain MRI scanning showed a new focus at the right parietal lobe. The tumor progression was diagnosed and the patient received erlotinib (150 mg, daily; Roche, Welwyn Garden City, UK) treatment as the second line therapy from May 11, 2013. After one month of erlotinib treatment, the diffuse miliary nodes considerably reduced or disappeared. The brain lesion had disappeared completely as well, and the therapeutic evaluation was partial response (PR). The patient's disease progressed again after six months of treatment. Chemotherapy with $500 \mathrm{mg} / \mathrm{m}^{2}$ pemetrexed on day 1 (Lilly France), and carboplatin with AUC of $5 \mathrm{mg} / \mathrm{ml} / \mathrm{min}$ on day 1 (in cycles of 21 days) was administered afterward as a third line therapy. In December 2014, the patient remained alive and was receiving follow-up. During the erlotinib treatment, she complained of skin rashes on her face, chest and scalp, which were not adequately controlled with topical therapy. In addition, she experienced excessively elongated, curly and irregular growth of both eyelashes (Fig. 1) and a change of hair texture from straight and thick to curly, brittle and fine after one month of initiating erlotinib treatment. After one month of withdrawal of erlotinib while the disease progressed, the rashes on the patient's skin gradually disappeared and the hair and eyelashes gradually became normal.

Case 2. An 85-year-old male patient with a diagnosis of stage cT4N2M1b lung adenocarcinoma primarily located in the right lower lobe of the lung, metastasis in bilateral lungs, mediastinal lymph nodes, pleural membrane and bone had a EGFR mutation at exon 21 of $E G F R$ [c.2543C $>\mathrm{T}$ (p.P848L)], detected in the tumor tissue by direct Sanger sequencing test. PR was diagnosed after two cycles of chemotherapy with single pemetrexed $\left(500 \mathrm{mg} / \mathrm{m}^{2}\right.$ on day 1 , in cycles of 21 days). As maintenance therapy, the patient received erlotinib $(150 \mathrm{mg}$, daily) from April 21, 2011. All lesions reduced or disappeared gradually. The patient's disease slowly progressed after 20 months of treatment. He continued to receive erlotinib although the disease progressed rapidly in June 2013. Chemotherapy (single pemetrexed) has been concomitantly performed for two cycles as second line therapy. Therapeutic evaluation was 'stable disease'. The patient refused further chemotherapy and succumbed to their illness in November 13, 2013. During the single erlotinib treatment, the patient experienced severe skin rashes and/or acne on his face, chest and extremities, which improved with topical therapy (vitamin $\mathrm{E}$ emulsion). In addition, his eyelashes became excessively elongated, brittle and curly after 3 months initiation of erlotinib. However, while the patient received erlotinib together with pemetrexed, the skin reactions notably reduced and he temporarily stopped erlotinib treatment during the second chemotherapy. In total, the patient was administered erlotinib for 27 months. Although his disease progressed, he continued to exhibit trichomegaly and skin reactions. Following the withdrawal of erlotinib, his skin and eyelashes gradually became normal.

Case 3. A 68-year-old male patient with a diagnosis of stage cT1bN2M1b lung adenocarcinoma primarily located in the right upper lobe of the lung, metastasis to mediastinal lymph

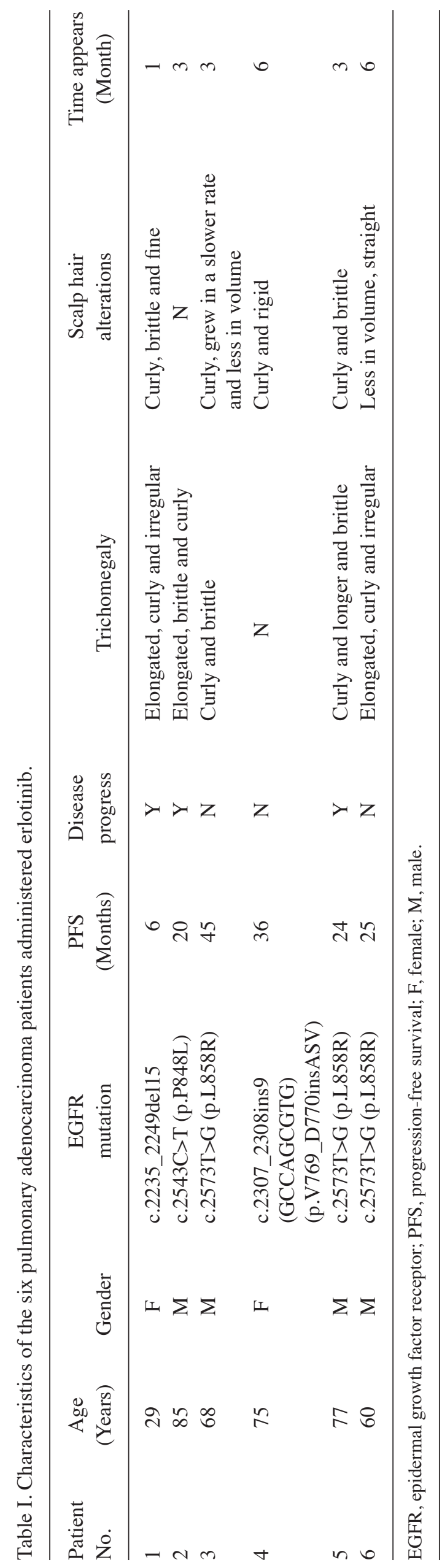



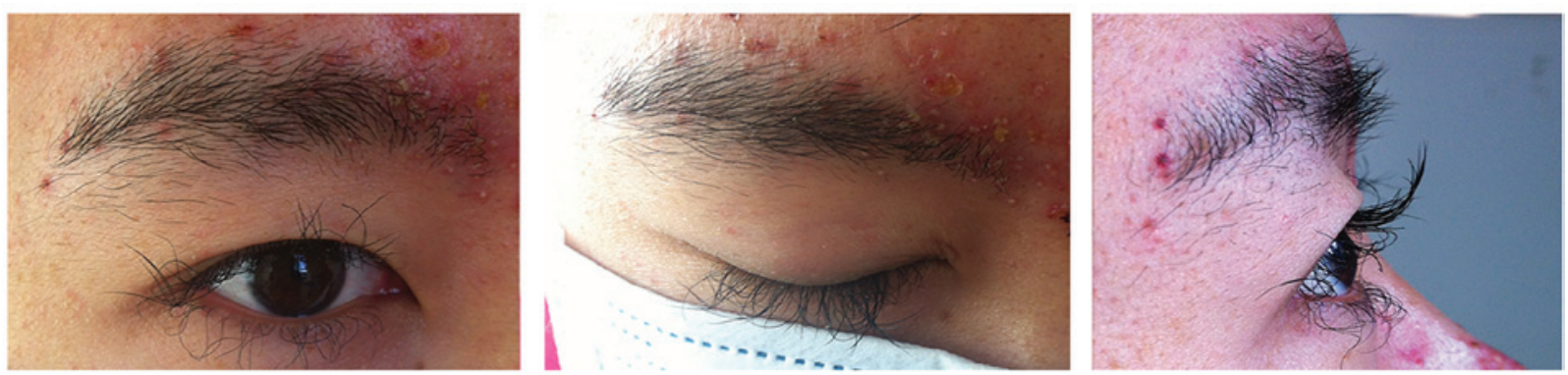

Figure 1. Eyelash trichomegaly in case 1. Patient's eyelashes became excessively elongated, curly and irregular during treatment with erlotinib.

A

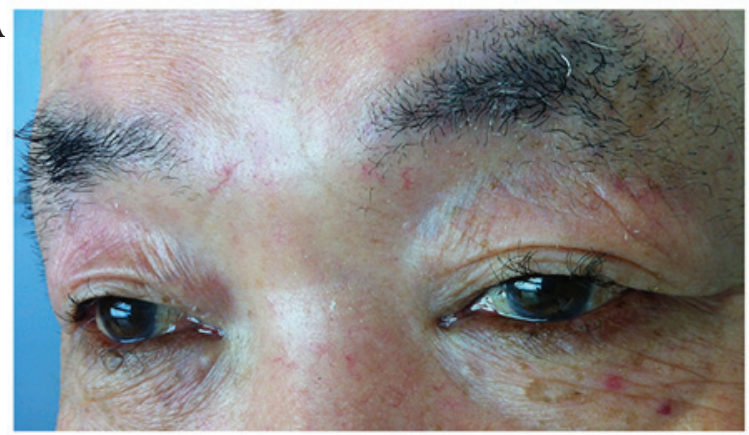

B

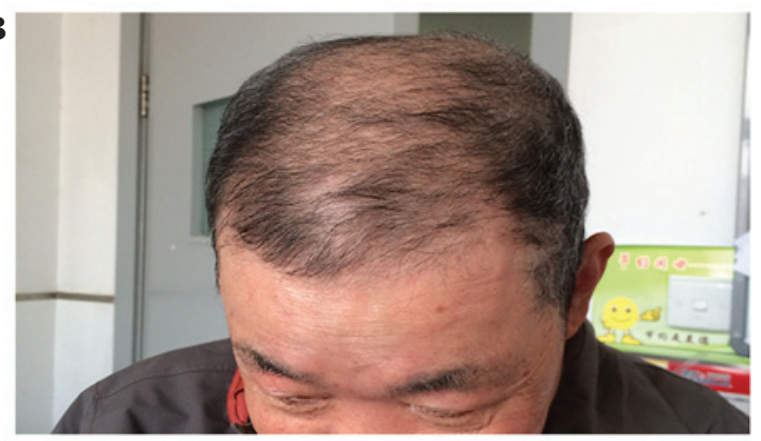

Figure 2. Eyelash trichomegaly and hair change in case 3. (A) Patient's eyelashes and eyebrows became curly and brittle and (B) his scalp hair became curly, grew at a slower rate and reduced in volume due to of hair loss during treatment with erlotinib.

nodes, pleural membrane and bone had EGFR mutations at exon 21 of EGFR [c.2573T>G (p.L858R)] detected by direct Sanger sequencing test. As second line therapy, the patient received erlotinib (150 mg, daily) from March 22, 2011. All lesions reduced or disappeared gradually. His disease remained stable as of December 22, 2014 (45 months of erlotinib). During the treatment, he experienced slight skin rashes on his face. His eyelashes and eyebrows became curly and brittle after 3 months of treatment with erlotinib (Fig. 2). Additionally, his scalp hair became curly, grew at a slower rate and reduced in volume (Fig. 2) due to hair loss. Since these side effects did not influence the patient's life quality, no treatment was performed.

Case 4. A 75-year-old female patient with a diagnosis of stage cT1bN0M1a lung adenocarcinoma primarily located in the right upper lobe of lung, metastasis in pleural membrane was administered erlotinib (150 mg, daily), starting December 12, 2011 as third line therapy. All lesions reduced or disappeared gradually. She underwent follow-up examinations every two months. Her disease remained stabled as of December 22, 2014 (36 months). Recently, the EGFR mutations were checked by amplification refractory mutation system test and the result showed that the patient has an insertion mutation at exon 20 (c.2307_2308ins9 (GCCAGCGTG) (p.V769_D770insASV). During the erlotinib treatment, the patient experienced slight skin rashes and diarrhea. There was no change at eyelashes, but the patient's hair became curly and rigid after 6 months of erlotinib treatment (Fig. 3). No management was performed since the side effects did not impact the patient's quality of life.

Case 5. A 77-year-old male patient had a confirmed diagnosis of stage IIIa (pT3N1M0) lung adenocarcinoma primarily

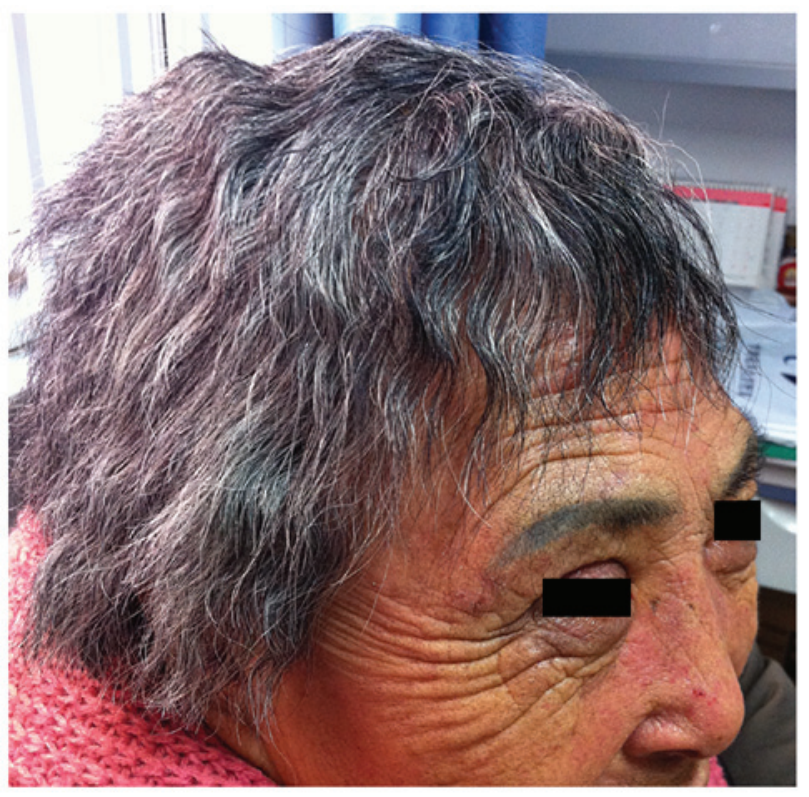

Figure 3. Alteration of scalp hair in case 4. Patient's hair became curly and rigid from straight and fine during treatment with erlotinib.

located in the left upper lobe of the lung, metastasis in left hilar lymph nodes was established through surgery. Adjuvant chemotherapy was administered as a single dose of docetaxel ( $75 \mathrm{mg} / \mathrm{m}^{2}$, in cycles of 21 days) for four cycles. The tumor had a missense mutation at exon 21 of EGFR [c.2573T $>\mathrm{G}$ (p.L858R)] by direct Sanger sequencing test. After his disease progressed, erlotinib (150 mg, daily) was administered as first line therapy from September 19, 2011. The patient's leg pain 
A

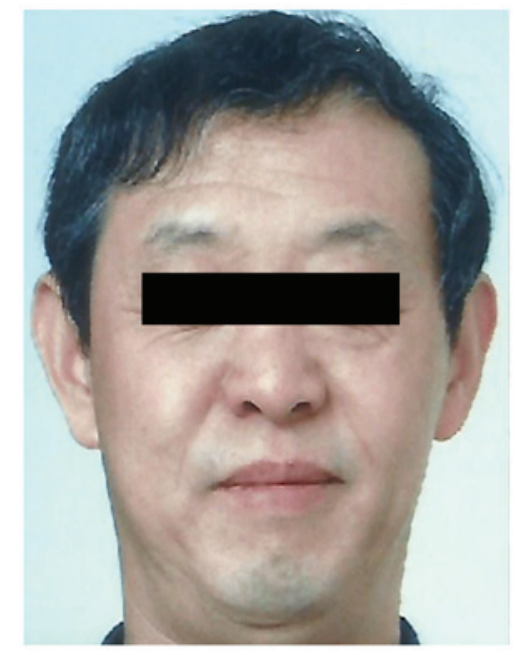

B

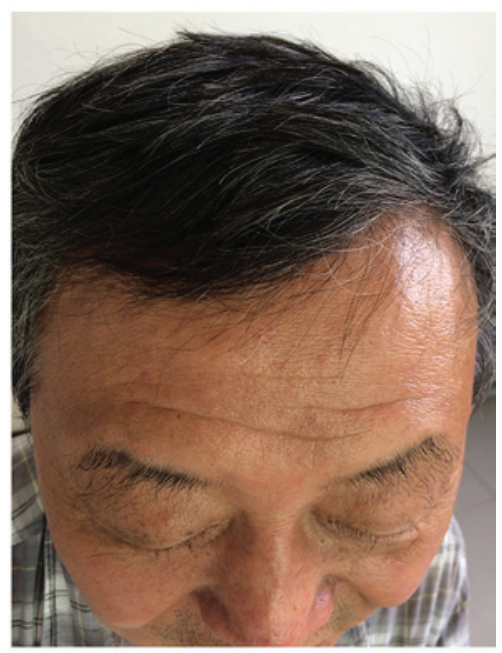

Figure 4. Alteration of scalp hair in case 6. Patient's hair became straight from curly during treatment with erlotinib. (A) Prior to and (B) after receiving erlotinib.

reduced considerably and the node in the lung disappeared. His disease progressed at September 2013. He refused further treatment and succumbed to his illness on October 23, 2013. The PFS of erlotinib is 24 months. During the erlotinib treatment, the patient experienced slight skin rashes and diarrhea. His eyelashes became curly, elongated and brittle, while his hair became curly and brittle as well after receiving 3 months treatment with erlotinib. No management was performed since these side effects did not affect his quality of life.

Case 6. A 60-year-old male patient with a diagnosis of stage cT4N2M1b lung adenocarcinoma primarily located in the left hilar and metastasis to mediastinal lymph node and bone tissues had a missense mutation at exon 21 of EGFR [c.2573T $>$ G (p.L858R)] by direct Sanger sequencing test. The patient received maintenance therapy with erlotinib (150 mg, daily) from December 2, 2012 as second line therapy. His disease remained stable as of December 22, 2014, and the PFS of erlotinib is 25 months. During the erlotinib treatment, the patient complained of severe skin rashes and acne on his face, neck, chest and scalp, which were not controlled well with topical therapy. In addition, the patient experienced slight diarrhea. The erlotinib administration was reduced from daily to 5-6 times per week with unchanged per dose $(150 \mathrm{mg})$, and the side effects mentioned above improved. In addition, the patient exhibited elongated, curly and irregular growth of his eyelashes, and his scalp hair volume reduced at 6 months after initiating erlotinib treatment. Notably, the patients hair became straight from curly after 6 months of treatment with erlotinib (Fig. 4). No management was performed since the side effects did not impact the patient's quality of life.

\section{Discussion}

EGFR is a transmembrane glycoprotein that is found on cells of epithelial origin and is expressed by solid tumors of several organs, including the lungs (19). EGFR tyrosine kinase inhibitors (EGFR-TKIs) have been developed and widely used in non-small-cell lung cancer patients (4-8). Erlotinib is one of EGFR-TKIs and used for the patients with activating mutations in the EGFR genes. The common side effects of erlotinib include rash, diarrhea, fatigue and loss of appetite (14). Herein, we describe rare side effects, trichomegaly and alterations of scalp hair in six pulmonary adenocarcinoma patients that received erlotinib.

Trichomegaly was initially reported in congenital diseases, such as Oliver-McFarlane syndrome (20). It was also described in acquired hypertrichosis in patients infected with HIV type 1 (21) or secondary to certain drugs such as zidovudine (22). In patients with lung cancer, trichomegaly uncommonly occurs after treatment with EGFR-TKIs, such as erlotinib (23-26) and gefitinib (14,27) or the EGFR monoclonal antibody, cetuximab (28). In the present cases, their eyelashes became curly, brittle, irregular and elongated after administration of erlotinib. The trichomegaly occurred after 1-6 months of therapy and it was reversible after cessation of the medication. EGFR mutations in the present cases were as following: Case 1 featured deletion at exon 19; cases 2, 3, 5 and 6 harbored a missense mutation at exon 21; and case 4 possessed an insertion mutation at exon 20. Case 2 possessed a p.L848R mutation but did not show similar scalp hair alterations as those reported in cases 3,5 and 6 with a p.L858R mutation. In addition, case 4 did not present eyelash trichomegaly as reported for other mutations in exons 19 and 21 . In the majority of cases, trichomegaly does not affect daily life and patients do not require special treatment, with certain patients actually preferring their appearance with trichomegaly. Trimming and epilation have been found to be satisfactory, safe therapeutic options in cases whose eyelashes grow excessively long.

Alteration of the scalp hair has been reported $(29,30)$ following the administration of EGFR inhibitors. In the present cases, patients experienced hair loss and a reduced growth rate, and commonly curly and brittle hair. However, in case 4, the patient's hair became curly but rigid (Fig. 3), which differed from the previous three cases. However, she did not exhibit eyelash trichomegaly, which was a different from the other five cases. Notably, she has a rare mutation, which is an insertion mutation at exon 20 (p.V769_D770insASV). The majority of exon 20 insertion mutations reported to date are associated 
with resistance to TKIs $(31,32)$. Her disease remained stable as of December 22, 2014, and the PFS is 36 months temporarily. The mechanism underlying the differing manifestations of these mutations is unclear. The hair became curly or straight, grew in fast or slow speed, does not need special treatment. However, cases of baldness which affects the appearance, the patient may need to consult a doctor.

The side effects of EGFR-TKI were predominantly cutaneous, including pruritis, xerosis, paronychia, skin fissures, telangiectasias and most commonly, acne form rash. These symptoms may be explained by the presence of EGFR in a variety of normal tissues in addition to lung tissue, including the basal layer of the epidermis and hair follicles and in sebaceous glands and capillaries. In contrast to other drug-associated skin changes, eyelash trichomegaly and alteration of scalp hair are not frequently observed; in one study of 30 patients receiving EGFR inhibitors, only 17\% (five individuals) noted an overgrowth of their eyelashes (33). These changes typically occur at 2-5 months after the start of treatment and may resolve in several weeks or months after discontinuation of the treatment.

However, different EGFR-TKIs produced side effects of varying severity. The discontinuation of erlotinib and gefitinib due to of toxic side effects occurs in 5 and $2 \%$ of patients, respectively $(14,34)$. Icotinib showed reduced toxicity compared with gefitinib ( $\mathrm{P}=0.05)$, with $0 \%$ of discontinuation (35). In previous clinical observations, no patients exhibited trichomegaly and alteration of scalp hair with icotinib treatment $(35,36)$.

In conclusion, trichomegaly and alterations of scalp hair are manifestations of erlotinib, which are uncommon, and generally do not affect patient quality of life. A relatively limited proportion of patients experience symptoms which influence daily life and require treatment. The detail mechanisms underlying these symptoms remain unknown and require further investigation.

\section{Acknowledgements}

The authors would like to thank all participating physicians and registered patients.

\section{References}

1. Torre LA, Bray F, Siegel RL, Ferlay J, Lortet-Tieulent J and Jemal A: Global cancer statistics, 2012. CA Cancer J Clin 65 87-108, 2015.

2. Ramalingam S and Belani C: Systemic chemotherapy for advanced non-small cell lung cancer: Recent advances and future directions. Oncologist 13 (Suppl 1): 5-13, 2008.

3. Blackhall FH, Shepherd FA and Albain KS: Improving survival and reducing toxicity with chemotherapy in advanced non-small cell lung cancer: A realistic goal? Treat Respir Med 4: 71-84, 2005.

4. Mok TS, Wu YL, Thongprasert S, Yang CH, Chu DT, Saijo N, Sunpaweravong P, Han B, Margono B, Ichinose Y, et al: Gefitinib or carboplatin-paclitaxel in pulmonary adenocarcinoma. N Engl J Med 361: 947-957, 2009.

5. Han JY, Park K, Kim SW, Lee DH, Kim HY, Kim HT, Ahn MJ, Yun T, Ahn JS, Suh C, et al: First-SIGNAL: First-line single-agent iressa versus gemcitabine and cisplatin trial in never-smokers with adenocarcinoma of the lung. J Clin Oncol 30: 1122-1128, 2012.

6. Wu YL, Zhou C, Liam CK, Wu G, Liu X, Zhong Z, Lu S Cheng Y, Han B, Chen L, et al: First-line erlotinib versus gemcitabine/cisplatin in patients with advanced EGFR mutation-positive non-small-cell lung cancer: Analyses from the phase III, randomized, open-label, ENSURE study. Ann Oncol 26: 1883-1889, 2015.
7. Yang JC, Wu YL, Schuler M, Sebastian M, Popat S, Yamamoto N, Zhou C, Hu CP, O'Byrne K, Feng J, et al: Afatinib versus cisplatin-based chemotherapy for EGFR mutation-positive lung adenocarcinoma (LUX-Lung 3 and LUX-Lung 6): Analysis of overall survival data from two randomised, phase 3 trials. Lancet Oncol 16: 141-151, 2015

8. Zhou C, Wu YL, Chen G, Feng J, Liu XQ, Wang C, Zhang S, Wang J, Zhou S, Ren S, et al: Final overall survival results from a randomised, phase III study of erlotinib versus chemotherapy as first-line treatment of EGFR mutation-positive advanced non-small-cell lung cancer (OPTIMAL, CTONG-0802). Ann Oncol 26: 1877-1883, 2015.

9. Solomon BJ, Mok T, Kim DW, Wu YL, Nakagawa K, Mekhail T, Felip E, Cappuzzo F, Paolini J, Usari T, et al; PROFILE 1014 Investigators: First-line crizotinib versus chemotherapy in ALK-positive lung cancer. N Engl J Med 371: 2167-2177, 2014.

10. Lynch TJ, Bell DW, Sordella R, Gurubhagavatula S, Okimoto RA, Brannigan BW, Harris PL, Haserlat SM, Supko JG, Haluska FG, et al: Activating mutations in the epidermal growth factor receptor underlying responsiveness of non-small-cell lung cancer to gefitinib. N Engl J Med 350: 2129-2139, 2004.

11. Paez JG, Jänne PA, Lee JC, Tracy S, Greulich H, Gabriel S, Herman P, Kaye FJ, Lindeman N, Boggon TJ, et al: EGFR mutations in lung cancer: Correlation with clinical response to gefitinib therapy. Science 304: 1497-1500, 2004.

12. Sharma SV, Bell DW, Settleman J and Haber DA: Epidermal growth factor receptor mutations in lung cancer. Nat Rev Cancer 7: 169-181, 2007

13. Yoshioka H, Mitsudomi T, Morita S, Yatabe Y, Negoro S, Okamoto I, Seto T, Satouchi M, Tada H, Hirashima T, et al: Final overall survival results of WJTOG 3405, a randomized phase 3 trial comparing gefitinib $(\mathrm{G})$ with cisplatin plus docetaxel $(\mathrm{CD})$ as the first-line treatment for patients with non-small cell lung cancer (NSCLC) harboring mutations of the epidermal growth factor receptor (EGFR). 2014 ASCO Annual Meeting Abstract Number: 8117. J Clin Oncol 32 (Suppl; abstr 8117): 5s, 2014.

14. Shah NT, Kris MG,Pao W, Tyson LB, Pizzo BM, Heinemann MH, Ben-Porat L, Sachs DL, Heelan RT and Miller VA: Practical management of patients with non-small-cell lung cancer treated with gefitinib. J Clin Oncol 23: 165-174, 2005.

15. Alexandrescu DT, Kauffman CL and Dasanu CA: The cutaneous epidermal growth factor network: Can it be translated clinically to stimulate hair growth? Dermatol Online J 15: 1, 2009.

16. Pinquié F, de Chabot G, Urban T and Hureaux J: Maintenance Treatment by Erlotinib and Toxic Cardiomyopathy: A Case Report. Oncology 90: 176-177, 2016.

17. Macerelli M, Mazzer M, Foltran L, Cardellino GG and Aprile G: Erlotinib-associated interstitial lung disease in advanced pancreatic carcinoma: A case report and literature review. Tumori 101: e122-e127, 2015.

18. Celik T and Kosker M: Ocular side effects and trichomegaly of eyelashes induced by erlotinib: A case report and review of the literature. Cont Lens Anterior Eye 38:59-60, 2015.

19. Hirsch FR, Varella-Garcia M and Cappuzzo F: Predictive value of EGFR and HER2 overexpression in advanced non-small-cell lung cancer. Oncogene 28 (Suppl 1): S32-S37, 2009.

20. Oliver GL and McFarlane DC: Congenital trichomegaly: With associated pigmentary degeneration of the retina, dwarfism, and mental retardation. Arch Ophthalmol 74: 169-171, 1965.

21. Kaplan MH, Sadick NS and Talmor M: Acquired trichomegaly of the eyelashes: A cutaneous marker of acquired immunodeficiency syndrome. J Am Acad Dermatol 25: 801-804, 1991.

22. Klutman NE and Hinthorn DR: Excessive growth of eyelashes in a patient with AIDS being treated with zidovudine. N Engl J Med 324: 1896, 1991.

23. Carser JE and Summers YJ: Trichomegaly of the eyelashes after treatment with erlotinib in non-small cell lung cancer. J Thorac Oncol 1: 1040-1041, 2006.

24. Lane K and Goldstein SM: Erlotinib-associated trichomegaly. Ophthal Plast Reconstr Surg 23: 65-66, 2007.

25. Braiteh F, Kurzrock R and Johnson FM: Trichomegaly of the eyelashes after lung cancer treatment with the epidermal growth factor receptor inhibitor erlotinib. J Clin Oncol 26: 3460-3462, 2008.

26. Wang SB, Lei KJ, Liu JP and Jia YM: Eyelash trichomegaly following treatment with erlotinib in a non-small cell lung cancer patient: A case report and literature review. Oncol Lett 10: 954-956, 2015.

27. Pascual JC, Bañuls J, Belinchon I, Blanes $M$ and Massuti B: Trichomegaly following treatment with gefitinib (ZD1839). Br J Dermatol 151: 1111-1112, 2004 
28. Bouché O, Brixi-Benmansour H, Bertin A, Perceau G and Lagarde S: Trichomegaly of the eyelashes following treatment with cetuximab. Ann Oncol 16: 1711-1712, 2005.

29. Price TJ and Nott L: Unusual hair changes with prolonged erlotinib exposure. Intern Med J 38: 807, 2008.

30. Becker A, van Wijk A, Smit EF and Postmus PE: Side-effects of long-term administration of erlotinib in patients with non-small cell lung cancer. J Thorac Oncol 5: 1477-1480, 2010.

31. Naidoo J, Sima CS, Rodriguez K, Busby N, Nafa K, Ladanyi M, Riely GJ, Kris MG, Arcila ME and Yu HA: Epidermal growth factor receptor exon 20 insertions in advanced lung adenocarcinomas: Clinical outcomes and response to erlotinib. Cancer 121: 3212-3220, 2015.

32. Yang M, Xu X, Cai J, Ning J, Wery JP and Li QX: NSCLC harboring EGFR exon-20 insertions after the regulatory C-helix of kinase domain responds poorly to known EGFR inhibitors. Int J Cancer 139: 171-176; Epub ahead of print, 2016.
33. Roé E, García Muret MP, Marcuello E, Capdevila J, Pallarés C and Alomar A: Description and management of cutaneous side effects during cetuximab or erlotinib treatments: A prospective study of 30 patients. J Am Acad Dermatol 55: 429-437, 2006.

34. Shepherd FA, Rodrigues Pereira J, Ciuleanu T, Tan EH, Hirsh V, Thongprasert S, Campos D, Maoleekoonpiroj S, Smylie M, Martins R, et al; National Cancer Institute of Canada Clinical Trials Group: Erlotinib in previously treated non-small-cell lung cancer. N Engl J Med 353: 123-132, 2005.

35. Shi Y, Zhang L, Liu X, Zhou C, Zhang L, Zhang S, Wang D, Li Q, Qin $\mathrm{S}$, et al: Icotinib versus gefitinib in previously treated advanced non-small-cell lung cancer (ICOGEN): A randomised, double-blind phase 3 non-inferiority trial. Lancet Oncol 14: 953-961, 2013.

36. Zheng H, Wang Q, Shi H, Zhang H, Hu F and Li B: Favorable response to icotinib in a lung cancer patient with a special mutation at exon 19 of epidermal growth factor receptor. Thorac Cancer 5: 358-361, 2014. 